Valchinov, V. (2021). Trends in the development of investments from business angels in Europe and Bulgaria. Actual Issues of Management Development. European Scientific e-Journal, 8 (14), 53-66. HlučínBobrovníky: "Anisiia Tomanek" OSVČ. (in Bulgarian)

Вълчинов, В. (2021). Тенденции в развитието на инвестициите от бизнес ангели в Европа и Бъцгария. Actual Issues of Management Development. European Scientific e-Journal, 8 (14), 53-66. HlučínBobrovníky: "Anisiia Tomanek" OSVČ.

DOI: $10.47451 / \operatorname{man} 2021-10-001$

EOI: $10.11244 / \operatorname{man} 2021-10-001$

The paper is published in Crossref, Internet Archive, ICI Copernicus, Google Scholar, Academic Resource Index ResearchBib, JGate, ISI, CiteFactor, eLibrary databases.

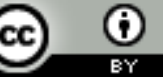

Vladislav Valchinov

$\mathrm{PhD}$ Student in Industrial Business Department of Industrial Business and logistics

Faculty of Economics

University of Economics - Varna

Varna, Bulgaria

Email: vladislav.valchinov@ue-varna.bg

\title{
Trends in the development of investments from business angels in Europe and Bulgaria (in Bulgarian)
}

\section{Abstract:}

Investments by business angels represent a relatively new approach to financing businesses in the initial phase of their development. The size of the market in Europe has been on the rise in recent years, reaching 8.04 billion. Thus, funding through business angels is becoming an important part of the tools that SMEs can use. A relatively small share of this amount is invested in Bulgaria, while some of the traditionally largest recipients of business angel investments are positioned in Europe. This gives rise to the goal of identifying trends in the development of the investment market by business angels in Europe and Bulgaria. More in-depth knowledge in this area will help to form steps for further development. Comparative, historical, logical and analytical methods were used to fulfill the objectives of the study. The author concludes that the key role is played by the individual characteristics of the business angels, as well as the characteristics of the sectors. The propensity to invest in technological and innovative enterprises is favorable for Bulgaria due to the development of the ICT sector of the country. Concrete steps are also needed to support through incentives and regulations.

\section{Keywords:}

business angels, Bulgaria, Europe, investments, initial phase of development, entrepreneurship, funding.

ВАадислав ВъАчинов Аокторант в докторантска програма „Индустриален бизнес“ КатеАра „Индустриален бизнес и могистика“ Стопански факултет 
Икономически университет - Варна

Варна, Бъмгария

Email: vladislav.valchinov@ue-varna.bg

\section{Тенденции в развитието на инвестициите от бизнес ангели в Европа и Бъмгария}

Резгоме:

Инвестициите от бизнес ангели представцяват сравнително нов подход във финансирането на бизнеси в началната фаза на тяхното развитие. Размерьт на пазара в Европа отбелязва тенденция към нарастване през последните години, като достига 8.04 млрА. евро. По този начин финансирането чрез бизнес ангели се преврыща във важна част от инструментариума, който могат Аа ползват МСП. Сравнително мальк Аял от тази сума се инвестира в България, Аокато едни от традиционно най-големите получатели на инвестиции от бизнес ангели са позиционирани в Европа. Това Аава повод поставянето на целта да бъдат идентифицирани тенденциите в развитието на пазара на инвестиции от

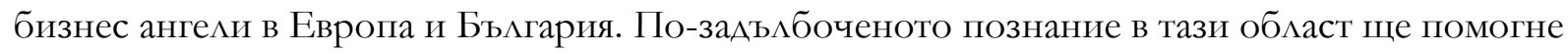
за формиране на стьпки за допьлнително развитие. За изпьлнението на целите на проучването са използвани сравнителни, исторически, Аогически и аналитични методи. Авторът заключва, че ключова роля имат индивидуалните характеристики на бизнес ангелите, както и характеристиките на секторите. Склонността към инвестиции в технологични и иновативни предприятия е благоприятна за Бъцгария поради развития ИКТ сектор на страната. Необходими са и конкретни стьпки за подкрепа чрез стимули и регулации.

Клточови думи:

бизнес ангели, Бъмгария, Европа, инвестиции, начална фаза на развитие, предприемачество, финансиране.

\section{Въведение}

През последните години се отдава все повече значение на предприемачеството и неговата роля на една от силите, Авижещи икономиката на страните. Аинамично и в множество направления се развиват тенденции, които Аопринасят и оформят предприемаческата екосистема. Нуждата от финансиране на предприятията в начална фаза на развитие създава условия за все по-голям Ая на инвестициите чрез собствен капитац. Популярни и със значителен Аял са тези на бизнес ангелите, субектите, предлагащи рисков капитал и краудфъндингът чрез продажба на Аял от преАприятието.

Явлението бизнес ангел се появява през 1980-те г. (Landström \& Sørheim, 2019), а през 2019 г. пазарът на инвестиции от бизнес ангели на ниво Европа достига до 8.04 млрА. евро. Неговата част от общия дял на инвестициите в 
начална фаза на развитие на бизнеса достига приблизително 61\% процента. Аанните следва да се разглеждат като ориентир, но не и като финални, тъй като АО голяма степен Аействията на този пазар остават скрити и вероятно не е известна голяма част от реалната стойност на инвестициите (EBAN Statistics Compendium European Early Stage Market Statistics, 2019). Текущите оценки на пазара се основават Ао голяма степен на екстраполации от удобни проби, които не могат Аа бъдат проверени за представителност, а резултатите варират значително межАу различните изследвания (Adveitchikova, 2008).

Целта на настоящото проучване е Аа бъдат идентифицирани тенденциите в развитието на пазара на инвестиции от бизнес ангели в Европа и Бъмгария. За Аа бъде постигната, са формирани следните задачи:

- Установяване на размера а пазара на инвестиции от бизнес ангели в Европа;

- Установяване на кАючови тенденции, произхождащи от десетте страни с най-развит пазар на инвестиции от бизнес ангели в Европа;

- Изясняване на характеристиките на инвестициите и инвеститорите Аемографски профил, обем и времеви хоризонт, секторни предпочитания;

- Установяване на размер и ключови характеристики на пазара на инвестицици от бизнес ангели в Бъцгария.

За изпълнението на целите на проучването са използвани сравнителни, исторически, Аогически и аналитични методи.

Изследването се базира основно на статистическите сборници на European Business Investment Organization (EBAN) за периода 2015-2019 г., както и на някои издания на Европейската Комисия. Използвана е информация и от Global Entrepreneurship Monitor и European Investment Fund. Подобен тип документи, генерирани на базата на мащабни проучвания, предлагат обхватна информация за изследваната проблематика. Автори като Landström и Sørheim, както и Mason и Adveitchikova представят ключови аспекти на теоретичната база и предлагат своята гледна точка.

\section{1. Размер на пазара на инвестиции от бизнес ангели}

Аефиницията на ЕК разглежАа бизнес ангелите като частни Аица, често с висока нетна стойност и обикновено с бизнес опит, които Аиректно 
инвестират част от своите активи в нов и нарастващ частен бизнес. „Бизнес ангелите“ могат да инвестират индивидуацно или като част от синдикат, където един „ангел“ обикновено поема водещата роля (European Commission). В тази Аефиниция на преден план излиза колективната и индивидуацна сица на инвеститорите и това, че разполагат със значителни капитали, които са готови да въвлекат. Аруга ключова конвенционална дефиниция посочва, че бизнес ангелите са инАивиАи с висока нетна стойност, които инвестират собствените си средства, заедно с времето и опита си, Аиректно в некотирани компании, в които инвеститорите нямат семейна връзка, с надеждата за финансова печалба (Mason, 2005). Така в кцючовите акценти се откроява и инвестирането на време и опит. Т.е. бизнес ангелът влага не само средства, но и знания, менторство, контакти и Ар. По този начин той преАпазва инвестицията си от определени рискове и осигурява редица необходими за нейното развитие фактори.

Възможността да се финансира чрез обемни суми и слел това до висока степен да се оказва многоаспектно влияние върху инвестицията я превръща в привлекателен инструмент. Това показват и данните на EBAN от последните години. В табл. 1 са разгледани общата и индивидуалната стойност на инвестициите в начална фаза на развитие на бизнесите в Европа за периода 2015-2019 (EBAN 2015-2019).

Информацията, поместена в таблицата, дава възможност Аа се проследят някои кАючови тенденции. При общата стойност на пазара на инвестиции в начална фаза на развитие се наблюдава движение в положителна посока през годините. Подобен характер на тенденцията може да бъде наблюдаван и в категориите на бизнес ангелите и рисковия капитац в начална фаза на развитие на бизнесите. При краудфъндинга се наблюдават известни колебания, но и тук проличава развитието на пазара в положителна посока. Аържателя на найголям Аял са именно бизнес ангелите. Размерът на сумата там нараства с противоречиви темпове. През 2016 увеличението е в размер на приблизително 10\%, през следващата година 9\%, докато през 2018 то е едва 2\%, тенденцията се възвръща през 2019 г., когато нарастването е с 8\% спрямо предходната година. Средният темп на нарастване е приблизително 7\%.

Във фиг. 1. може да бъде проследена динамиката на данните от табл. 1. Положителното Авижение при категориите е лесно проследимо. Изключение прави краудфъндингът, поради сравнително по-ниската стойност спрямо останалите показатели. От представените Аанни ясно Аичи и позицията на отАелните видове инвестиции. Табл. 2. представцява по-залъцбочен поглеА върху тези позиции, защото те са изразени процентно. Става ясно, че за 
периода 2015-2019 г. делът на инвестициите с произход бизнес ангели показва тенденция към спадане. Основната причина за това явление е, че обемът на инвестициите чрез рисков капитал нараства с по-голям мащаб, спрямо Аельт на тези от бизнес ангелите.

От изведената информация може да бъдат направени следните заключения по отношение на инвестициите на бизнес ангели:

- Инвестициите от бизнес ангели имат не само финансово изражение. Те са съпътствани от менторство, специфично ноу-хау, опит, контакти и Ар. ресурси.

- Обемът на инвестициите от бизнес ангели е с най-висока стойност в сравнение с останалите разглежлани вилове финансиране за бизнеса в начална фаза на развитие за Европа. Техният Аял устойчиво се задържа наА 60\% от общия през обхванатия от изследването период;

- Обемът на инвестициите от бизнес ангели намалява като процентно отношение спрямо останалите видове финансиране, което вероятно се АъАжи на тяхната по-висока степен на нарастване.

По този начин, пазарът на инвестиции от бизнес ангели е Аинамичен и расте ежегодно в парично изражение. Това дава възможност да се приеме, че възвръщаемостта за инвеститорите е удовлетворяваща и те го възприемат като подходящо място за капиталовложение. Причините могат Аа се коренят в повисоката степен на оказван контрол от тяхна страна, както и предоставянето на Аостып до специфичните ресурси на инвестирора. В това число - менторство, знания, опит, контакти и Ар. Аинамиката на пазара може Аа бъде акурантно представена и чрез конкретни примери от Европа.

\section{2. Тенденции в инвестициите на бизнес ангели в Европа}

\section{1. Обем на финансирането и участници}

ЗаАълбоченият анализ върху проявлението на тенденции в инвестициите от бизнес ангели може да бъде постигнат чрез преглед на данните от десет страни, които традиционно са среА най-големите получатели на финансиране от този тип. Анализът се базира на издаденият последно статистическия сборник на EBAN от 2019 г. Тъй като организацията следи състоянието на пазара на инвестиции от бизнес ангели в начална фаза на развитие на фирмите на ниво Европа, а не на ниво ЕС, са включени и страни извън Съюза. Информацията за страните е посочена в табл. 3., която е коригирана за целите 
на изследването и обхваща т. нар. видим пазар, т.е. инвестициите, които са осъществени публично.

Табл. 3 обхваща общата сумата на инвестициите като въвежла и броя на организациите на бизнес ангели и съответно броя на инвеститори. По редица икономически причини Обединеното кралство е на първо място по всички показатели. Спрямо следващата страна от списъка - Германия - се формира почти Авойна разАика по обща сума на инвестициите и по броя на организациите. По брой на инвеститорите разциката е четири пъти по-голяма. Това явление оказва влияние върху средната инвестиция при отношението на броя на инвеститорите и общата сума на инвестициите. При останалите страни се забелязва относително прогресивно намаляване на общатата стойност на инвестициите, което може Аа бъде представено с фиг. 2. Съществен скок се наблюдава между страна 3 и страна 4 (Испания и Финландия). По отношение на останалите Аве категории, представени в таблицата, трудно би могло Аа бъде установена определена тенденция. Интерес представцява Франция, където има относително висок брой на организации и инвеститори и сравнително ниска обща сума на инвестиции спрямо останалите страни.

Разглежданите страни са показателни поради тяхната икономическа позиция в Европа и света. Значителна част от извадката е изградена от участници в международният форум G20. От Аруга страна, подобен тип инвестиции имат тясна връзка с развитието на преАприемачеството, среА чиито измерители е ГАобалният предприемачески индекс - GEDI. По Аанни за 2018 г. страните от извадката са на челни позиции. Изключение правят Русия и Италия, които са последни и в текущо разглежАаната извадка (GEDI). Отношението межАу инвестиции от бизнес ангели и БВП Аава различна перспектива. От разглежданата извадка Финландия, Аания и Швеция (в този реА) показват най-висока активност по този показатец, като наАхвърлят средната за Европа (EBAN Statistics Compendium European Early Stage Market Statistics, 2018).

Така от изслеАването в европейски Аържави с траАиционно високи нива на активност от бизнес ангели може да се направи заключение на базата на техните икономически показатели. Изглежда, че този тип инвеститори са благоприятствани от Аобрата предприемаческа екосистема и подобен метод на финансиране се развива активно на утвърдените пазари с висок БВП.

\section{2. Характеристики на инвестициите и инвеститорите}


По същество финансирането от бизнес ангели има конкретни характеристики, които могат да бъдат класифицирани с оглед на демографския профил на бизнес ангелите, обема на тяхното финансиране, предпочитаните сектори и Ар.

Характерно за бизнес ангелите е, че в повечето случаи са индивиди с богат опит. По-голямата част от тях е на възраст наА 55 г. Тази тенденция има поразлично проявление в Източна Европа, където възрастта пада до 43 г. Аруга значима характеристика на този тип инвеститори е тяхната висока степен на образованост. Почти всички разполагат със степен на образование бакацавър или по-висока. Около 50\% разполагат с магистьрска степен и приблизително 17\% с докторска такава. От гледна точка на своята кариера по-голямата част от бизнес ангелите е постигнаца опит или чрез корпоративната среда на високи мениджьрски позиции, или чрез развитие на успешен собствен бизнес. Аоста често и двете. По-рядко бизнес ангелите са представители на НПО или Аържавни организации (Understanding the Nature and Impact of the business angels in Funding Research and Innovation, 2017).

Традиционно бизнес ангелите търсят Аългосрочни възможности, към които да насочат своите средства. Периодите, в които се разгръщат инвестициите, обикновено Аостигат до межАу пет и Аесет години. Понякога повече. От Аруга страна, размерът на общото финансиране от инвеститор варира от 22 хил. евро до наА 3 млн, като медианата е поставена на 231 хил. евро (Understanding the Nature and Impact of the business angels in Funding Research and Innovation, 2017).

Европейският инвестиционен фонА изследва въздействието на бизнес ангелите на ниво ЕС, като Аостига някои важни изводи. Оказва се, че едни от най-значимите сектори, получаващи инвестиции, са информационните и телекомуикационните технологии, сферата на услугите, т. нар науки за живота, чистите технологии, както и сферата на производството. Първите позициии в портофмиото на инвеститоите са заемани от изкуствен интелект (AI), машино обучение, цифрово зАраве, електронна търговия, възобновяема енергия, киберсгируност и финтех решения (Kraemer-Eis, p. 5-6). Аруги проучвания потвърждават тази информация (EBAN Statistics Compendium European Early Stage Market Statistics, 2018).

По този начин, заможността, опитьт и образованието като изходни позиции дават на бизнес ангелите необходимата база за осъществяване на Аоходоносни инвестиции. За това свидетелства и възрастовият диапазон като фактор за натрупването на необходимата подготовка. Отражение дава най- 
вече опитьт на инвеститорите като предприемачи и мениАжьри. Времевият хоризонт на инвестициите може Аа бъде характеризиран като благоприятен. Обемът на сумите варира. Предпочитанията за инвестиции са предимно в технологичния сектор и направленията, които могат Аа бъдат характеризиране като иновативни и разрешаващи актуални проблеми на обществото.

\section{3. Тенденции в инвестициите на бизнес ангеми в БъАгария}

Статистически сборници, на които Ао голяма степен се базира изследването, Аават кАючова информация за изследвания период и за Бълария, чиято позиция спрямо разглежАаните в предходната точка Аържави е Авадесет и втора. Общата сума на проследимите инвестиции е в размер на 4.26 млн. евро. Има четири организации, свързани с инвестициите на бизнес ангели и сто инвеститори. Броя на инвестициите е осем (EBAN Statistics Compendium European Early Stage Market Statistics, 2019).

Ако бъдат проследени Аанни за предходни години, могат да бъдат установени определени тенденции в развитието на този тип инвестиции в страната. В табл. 4 може Аа се установи Авижението на общите суми на финансиране, както и процентното изменение спрямо предходни години (EBAN 2018-2019). От таблицата е видимо, че разглежАания период минава през три етапа - положителна теденция през периода 2015-2016 г., връх през 2017 г. и отрицателна тенденция през периода 2018-2019 г. Обемите на нарастване и на намаляване на общата сума са относително сходни.

От извършения анализ на състоянието на пазара на инвестициите от бизнес ангели на европейско ниво може Аа бъде установено, че Бъцгария значително изостава в това отношение. Спрямо тридесет и осемте Аържави Бъцгария се намира на двадесет и второ място по размер на инвестициите с такъв произход. От тук следва, че са нужни конкретни действия за създаването на положителна тенденция, която Аа се развива устойчиво. Традиционно тези Аействия се свързват с конкретни политики - най-често в сферата на икономическата политика. Тъй като по същество бизнес ангелите финансират предприемачески инициативи, би следвало Аа се тьрси връзката межАу тези две категории. Аокладът на GEM за Бъцгария от 2016/2017 извежда ключови препоръки в областта на развитието на предприемачеството. СреА тях са осигуряването на менторство от страна на утвърдени фирми, стимулиране на финансови инструменти, базирани на пазара, по-добро сътрудничество с професионални бизнес организации и разширяване на възможностите за финансиране (Andonova \& Krasteva, 2017). Работата с бизнес ангели може Аа 
бъде част от решението на тези препоръки. За разАика от Аруги методи на финансиране тук често се осигурява достъп и до Аруги кАючови ресурси като контактна мрежа и менторство. Като частни инвеститори, които извършват своята дейност с цел печалба, те са задвижвани чрез пазарните механизми.

Аопълнителна Аълбочина Аава Глобалният предприемачески индекс, като той поставя страната на 69-то място, като я отдалечава от челните позиции. От разглежАаните в настоящето изследване държави само Русия е на по-задна позиция (GEDI). По отношението межАу инвестиции от бизнес ангели и БВП страната се представя под средното ниво, но предхожда страни като Германия, Русия, Италия и Франция. Това е индикатор за значението на подобен тип инвестиции за българската икономика.

От гледна точка на бизнеса страната се развива като хъб за стартиращи предприятия в сферата на IT (EBAN Statistics Compendium European Early Stage Market Statistics, 2018), което до голяма степен кореспондира с предпочитанията на бизнес ангелите. От Аруга страна, както стана ясно от анализа, средната възраст на бизнес ангелите в Източна Европа е 43 г., което спомага за неутрализирането на възрастта като фактор за разбиране и инвестиране в модерните сектори.

По същество тенденциите при бизнес ангелите в България са до голяма степен сходни с тези при успешните примери от Европа. Развитието на ИКТ сферата би могло да е основен магнит за генерирането на по-голям обем инвестиции. Съществен стълб на развитие следва да бъде добре развитата преАприемаческата екосистема, която Ао голяма степен зависи и от политиките на страната. ЕАинственият правен документ, в който се споменават бизнес ангелите е Националната стратегия за насърчаване на МСП 2014-2020 г. (EBAN Statistics Compendium European Early Stage Market Statistics, 2019), Oт което следва, че съществува поле за работа по тематиката.

\section{Аискусия}

Инвестициите, предоставени от бизнес ангели, са допълнение към инструментариума за финансиране на МСП. Ето защо те преАставляват интерес както за предприемачите, така и за изследователите. Тенденцията за нарастване на техния пазар от последните години е силен индикатор за добавената стойност, която генерират. На база на извършения анациз могат Аа бъдат Аостигнати конкретни изследователски въпроси, които предстои Аа бъдат разглеждани в следващи публикации. 
Интерес представлява пазарът на подобен тип инвестиции, както и неговите характеристики. Впечатление правят определени тенденции в конкретни страни от ЕС. Тяхното изясняване би могло Аа доведе Ао трансфер на Аобри практики и развитие на пазарите и в Аруги страни. В този случай Бъцгария. Това направление би могло Аа се развие чрез опити за идентифицирането на конкретни стьпки, на чиято база да бъде развит пазарьт на инвестиции от бизнес ангели в страната.

От Аруга страна, получателите на финансиране от бизнес ангели споделят някои общи характеристики. Това важи и за предоставящите финансиране инвеститори. ЗаАъцбоченият анализ на тези особености би могъ $А$ Аа АовеАе АО откриване на начини за повишаване на ефективността от инвестициите.

\section{Закиючение}

Бизнес ангелите Аопълват възможностите за финансиране на бизнеса в неговата начална фаза на развитие, разширявайки спектьра на подкрепа чрез преАлагането на менторство, знания, опит и Ар. ресурси. Тази допълнителна грижа позволява на инвеститорите Аа увеличат шанса за успех на своите инвестиции. Европейският пазар се оказва благоприятен за този тип финансиране. Като слеАствие той увеличава обема си през последните години. Оказва се, че страните с Аобре развита предприемаческа екосистема, които традиционно са икономически силни, са отлична среда за развитието на инвестициите от бизнес ангели. Върху методът на финансиране активно влияят, както характеристиките на самите бизнес ангелите, така и характеристиките на съответния сектор. Фокусът е поставен най-вече върху технологичността и иновациите. Това Аава възможност и на България Аа се възползва от инвестициите с подобен произход заради своя развит ИКТ сектор. ПреАприемаческата екосистема е Аруг кАючов фактор за развитието на подобен пазар. И още повече нейното политическо прояв^ение в смисьца на стимули, регулации и Ар. Макар и назаА в общата картина по обем на пазара, по Аруги параметри се наб̆ююдават сходства межАу европейските страни и

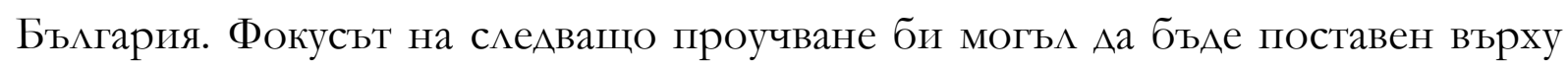
формирането на стьпки за развитието на пазара на инвестиции от бизнес ангели в страната.

\section{Източници на информация:}


Adveitchikova, S. (2008). On the structure of the informal venture capital market in Sweden: developing investment roles. Venture Capital, 10, 55-85. Informa UK Limited.

Andonova, V. \& Krasteva, M. (2017). 2016/17 GEM National report on Entrepreneurship in Bulgaria. Global Entrepreneurship Monitor Bulgaria Association Sofia.

EBAN Statistics Compendium European Early Stage Market Statistics 2018 (November 26, 2018). European Angel Investment Summit. Brussel.

EBAN Statistics Compendium European Early Stage Market Statistics 2019. Retrieved October 15, 2021 from https://www.eban.org/eban-statisticscompendium-2019/

European Comission, Business angels. Retrieved October 18, 2021 from https:// ec.europa.eu/growth/access-to-finance/funding-policies/businessangels en

Kraemer-Eis, H., Botsari, An., Brault, J., \& Lang, Fr. (2019). EIF Business Angels Survey. Working Paper, 60. European Investment Fund.

Landström, H. \& Sørheim, R. (2019). The ivory tower of business angel research. Venture Capital, 21, 97-119. Informa UK Limited.

Mason, C. (2005). Business angel investing. Personal Wealth Management: How to Ensure Maximum Investment Returns with Security, 169-175. Kogan Page.

The Global Entrepreneurship and Development Institute, Global Entrepreneurship Index. Retrieved October 19, 2021 from https://thegedi.org/

Understanding the Nature and Impact of the business angels in Funding Research and Innovation. Final Report (2017). Business Angels Funding (BAF). European Commission. Center for European Scientific Research. 


\section{Приможения}

Табл. 1. Аялове и обща стойност на инвестициите в начална фаза на развитие на бизнесите в Европа

\begin{tabular}{|c|c|c|c|c|c|}
\hline & 2015 & 2016 & 2017 & 2018 & 2019 \\
\hline $\begin{array}{l}\text { Аял на инвестициите от бизнес } \\
\text { ангели в (млрд. евро) }\end{array}$ & 6.1 & 6.7 & 7.3 & 7.45 & 8.04 \\
\hline $\begin{array}{l}\text { Аял на инвестицциите в } \\
\text { начална фаза на развитие чрез } \\
\text { рисков капитал (млрА. евро) }\end{array}$ & 2.1 & 2.5 & 3.5 & 4.13 & 4.4 \\
\hline $\begin{array}{l}\text { Аял на инвестициите чрез } \\
\text { краудфъндинг срещу Аял от } \\
\text { предприятието (мАрА. евро) }\end{array}$ & 0.4 & 0.7 & 0.63 & 0.78 & 0.78 \\
\hline $\begin{array}{l}\text { Обща стойност на } \\
\text { инвестициите в начална фаза } \\
\text { на развитие (м^рд. евро) }\end{array}$ & 8.6 & 9.9 & 11.4 & 12.3 & 13.22 \\
\hline
\end{tabular}

Таблица 2. Процентно съотношение на категориите инвестиции в начална фаза на развитие на бизнесите

\begin{tabular}{|c|c|c|c|c|c|}
\hline & 2015 & 2016 & 2017 & 2018 & 2019 \\
\hline $\begin{array}{l}\text { Аял на инвестициите от бизнес } \\
\text { ангели в (млрд. евро) }\end{array}$ & $71 \%$ & $68 \%$ & $64 \%$ & $60 \%$ & $61 \%$ \\
\hline $\begin{array}{l}\text { Аял на инвестицциите в } \\
\text { начална фана а азвитие чрез } \\
\text { рисков капитал (млрА. евро) }\end{array}$ & $24 \%$ & $25 \%$ & $31 \%$ & $34 \%$ & $33 \%$ \\
\hline $\begin{array}{l}\text { Ая на инвестициите чрез } \\
\text { краудфьндинг срещу дял От } \\
\text { предприятието (мАрА. евро) }\end{array}$ & $5 \%$ & $7 \%$ & $5 \%$ & $6 \%$ & $6 \%$ \\
\hline
\end{tabular}


Табл. 3. Състояние на пазара на инвестиции в десет от европейските страни с най-развит такъв пазар

\begin{tabular}{|l|c|c|c|c|}
\hline Страна & $\begin{array}{l}\text { Обща сума на } \\
\text { инвестициите от } \\
\text { бизнес анге } \\
\text { (млн. евро) }\end{array}$ & $\begin{array}{l}\text { Брой на } \\
\text { инвестициите } \\
\text { от бизнес } \\
\text { ангели в } \\
\text { съответната } \\
\text { страна }\end{array}$ & $\begin{array}{l}\text { Брой на } \\
\text { бизнес } \\
\text { ангелите }\end{array}$ & $\begin{array}{l}\text { Брой на } \\
\text { организациите } \\
\text { на бизнес ангели }\end{array}$ \\
\hline $\begin{array}{l}\text { Обединено } \\
\text { кралство }\end{array}$ & 153.08 & 882 & 9000 & 74 \\
\hline Германия & 81.77 & 176 & 2000 & 40 \\
\hline Испания & 78.66 & 296 & 3742 & 68 \\
\hline Финландия & 54 & 415 & 670 & 12 \\
\hline Швеция & 44.08 & 60 & 820 & 64 \\
\hline Франция & 43 & 422 & 5500 & 10 \\
\hline Аания & 33.34 & 209 & 250 & 24 \\
\hline Швейцария & 32.60 & 148 & 710 & 2 \\
\hline Италия & 28.20 & 73 & 450 & 250 \\
\hline Русия & 26.08 & 77 & & \\
\hline
\end{tabular}

Таблица 4. Състояние на пазара на инвестиции от бизнес ангели в България за периода 2015-2019 г.

\begin{tabular}{|c|c|c|c|c|c|}
\hline & 2015 & 2016 & 2017 & 2018 & 2019 \\
\hline 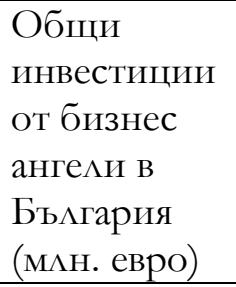 & 4,2 & 5 & 7 & 5,60 & 4,26 \\
\hline $\begin{array}{l}\text { Изменение } \\
\text { от година на } \\
\text { година }\end{array}$ & $\begin{array}{l}30 \% \text { спрямо } \\
\text { предходната } \\
2014 \text { г. }\end{array}$ & $\begin{array}{l}\text { 16,5\% спрямо } \\
\text { преАходната } \\
2015 \text { г. }\end{array}$ & $\begin{array}{l}40 \% \text { спрямо } \\
\text { предходната } \\
2016 \text { г. }\end{array}$ & $\begin{array}{l}-20 \% \text { спрямо } \\
\text { преАходната } \\
2017 \text { г. }\end{array}$ & $\begin{array}{l}-24 \% \text { спрямо } \\
\text { преАходната } \\
2018 \text { г. }\end{array}$ \\
\hline
\end{tabular}




\section{Изменение на видовете инвестиции за периода 2015-2019 г.}

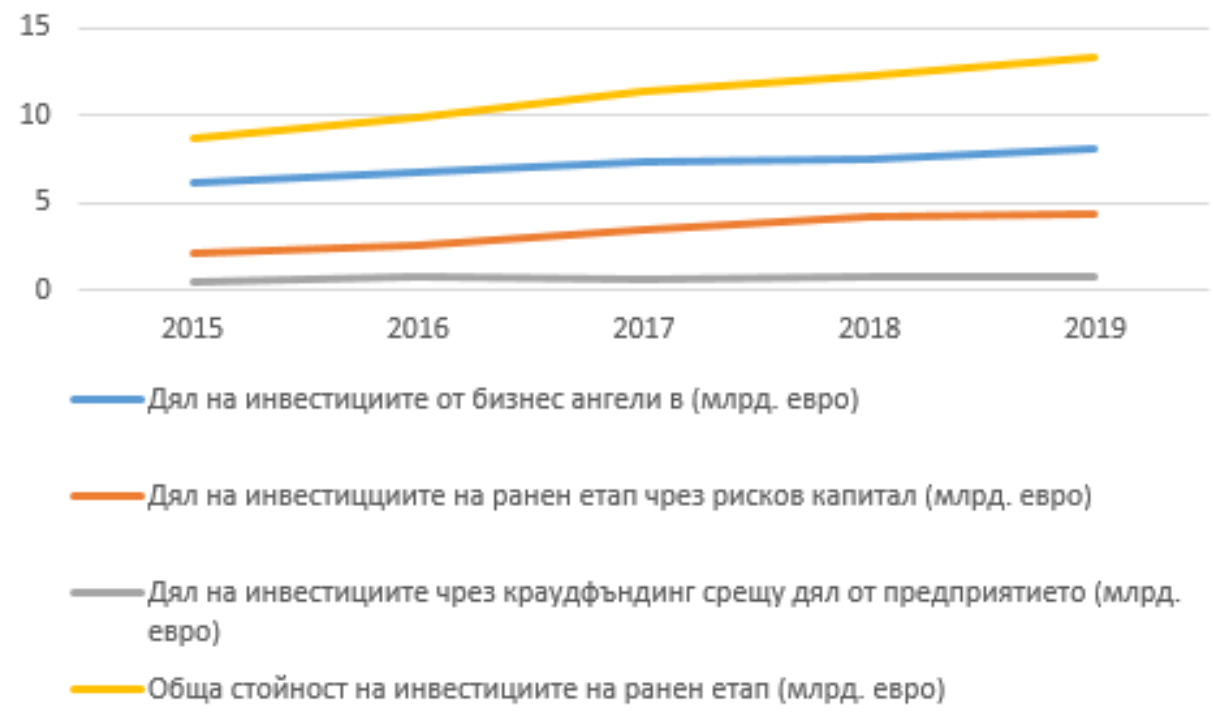

Фигура. 1. Изменение на категориите инвестиции в начална фаза на развитие по години

Обща сума на инвестициите от бизнес ангели

(млн. евро)

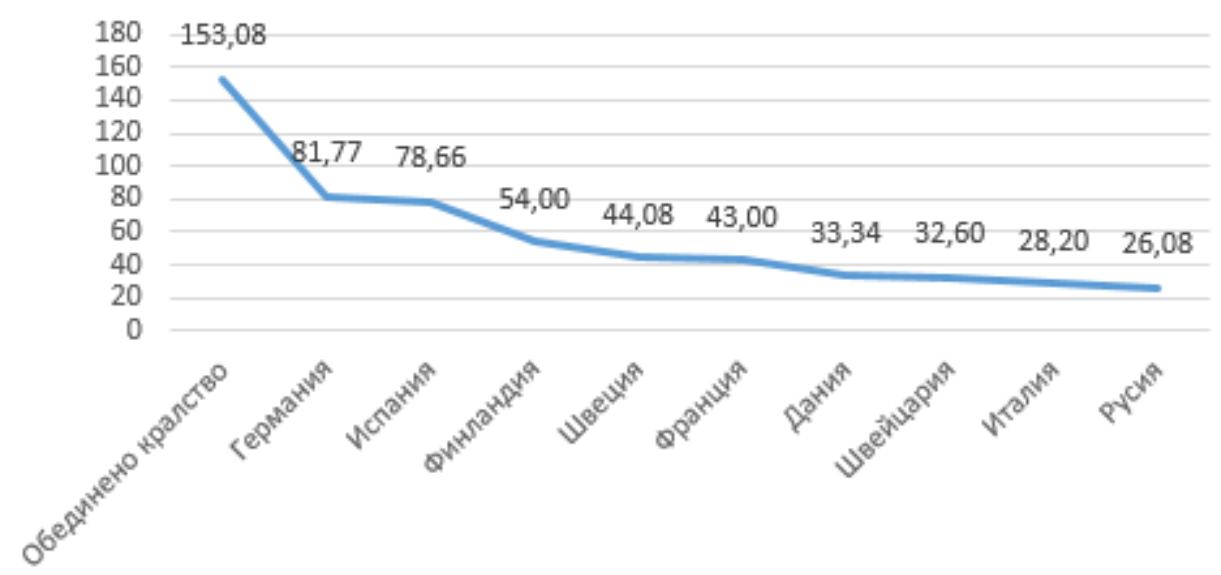

Фигура. 2. Обща сума на инвестициите от бизнес ангели (млн. евро) 